\title{
Functional shifts in estuarine zooplankton in response to climate variability and eutrophication
}

\author{
Anna Jansson ${ }^{1}$, Riina Klais ${ }^{2}$, Evelina Griniene ${ }^{3}$, Gunta Rubene ${ }^{4}$, Anna Semenova ${ }^{5}$, \\ Aleksandra Lewandowska ${ }^{6}$, and Jonna Engström-Öst ${ }^{1}$ \\ ${ }^{1}$ Novia University of Applied Sciences Raasepori Campus \\ ${ }^{2}$ Ecostat Ltd \\ ${ }^{3}$ Klaipeda University \\ ${ }^{4}$ Institute of Food Safety Animal Health and Environment \\ ${ }^{5}$ Atlantic Branch of the Russian Federal Research Institute for Fisheries and Oceanography \\ ${ }^{6}$ University of Helsinki
}

May 5, 2020

\begin{abstract}
Functional traits are becoming more common in the analysis of marine zooplankton community dynamics associated with environmental change. We use zooplankton groups with common functional properties to assess long-term trends in the zooplankton caused by certain environmental conditions in a highly eutrophicated gulf. Time series of zooplankton traits were collected since 1960 in the Gulf of Riga, Baltic Sea and were analysed using general additive model, principal component analysis, and multivariate model. One of the most significant changes was the considerable increase in the amount of the zooplankton functional groups (FGR) in coastal springtime communities, and dominance shifts from more complex to simpler organism groups - cladocerans and rotifers. The results also show that the functional trait organism complexity (body size) decreased considerably due to cladoceran and rotifer increase following elevated water temperature. Salinity and oxygen had negligible effects on the zooplankton community.
\end{abstract}

\section{Keywords}

climate change, complexity, functional group richness, functional traits, oxygen, salinity, zooplankton community,

\section{Introduction}

To detect changes in multispecies communities caused by environmental changes, the communities have traditionally been studied based on taxonomic classification of species, focusing on their abundance and diversity (Sherman et al. 1998). This approach, however, does not provide immediate information on the functioning and the ecological properties of the communities, but only on their composition. The functional traits can be used to provide information on how changes in the community might lead to changes in the functioning of the system (Hébert et al. 2017).

In the Baltic Sea area, like elsewhere in the world, warming and increasing precipitation are both accelerating due to global climate change. Warming of the Baltic Sea has continued since 1860 (MacKenzie \& Schiedek 2007; Belkin 2009) with a rate $1^{\circ} \mathrm{C}$ per decade in all sub-basins (Lehmann et al. 2011; BACC II Author Team 2015). A salinity decrease of ca. 1-2 units is expected by the end of this century due to more frequent rainfall and the subsequent rise in freshwater run-off from the catchment area (Meier et al. 2012; Holopainen et al. 2016). The increased riverine run-off also brings along more nutrients, impacting the eutrophication status of 
the Baltic Sea (Leppäranta \& Myrberg 2009). The Baltic Sea has been affected by severe eutrophication since the 1960s (Cederwall \& Elmgren 1980; Andersenet al. 2016). Due to a large increase in the production of organic matter and the subsequent increased oxygen demand during decomposition of the produced biomass, the Baltic Sea is also exposed to large-scale hypoxia (Conley et al. 2007; Andersen et al.2016). An increase in hypoxia due to rising temperatures and accelerated eutrophication in the Baltic Sea is predicted (Karlson et al.2002; Conley et al. 2009; Carstensen et al. 2014). These changes in environmental conditions modify populations and communities by impacting species distribution ranges, abundance and dominance relations, food-web structures and behavioral and physiological functions of species. Through these effects, the structure and functioning of whole ecosystems can be altered (Thomas et al.2004; Doney et al. 2012). Fish larvae and their recruitment to the population can be especially impacted if the quality of their food community i.e. zooplankton decreases substantially (Edwards \& Richardson 2004; Arula et al. 2014).

The aim of the current work is to study how the zooplankton community is associated with measured environmental variables in the Gulf of Riga using a hypothesis-driven approach. We expect that decreasing salinity, warming and decreasing oxygen affect zooplankton negatively. We also expect milder winters to reduce functional group richness (seeHypotheses ). The dataset is extensive and can readily be used to generalize patterns occurring in brackish areas as a consequence of environmental change.

\section{Material and methods}

\section{Study area}

The Baltic Sea is a shallow (mean depth $54 \mathrm{~m}$ ), strongly stratified brackish water sea with a topography consisting of several sub-basins, and is connected to the North Sea only by narrow straits allowing minimal water exchange with the fully marine North Atlantic Ocean (Leppäranta \& Myrberg 2009). It is characterized by substantial riverine input and steep geographical and seasonal gradients in temperature, salinity and nutrient concentrations. The salinity in the Baltic Sea is in some areas low, and ranges from 2 to 25 (Leppäranta \& Myrberg 2009).

The Gulf of Riga is located at temperate latitudes with mean summer air temperatures close to $20^{\circ} \mathrm{C}$, and in winter around -5degC. The gulf can be ice-covered up to 80 days (Kotta et al. 2008), but often winters can be ice-free too. Winter conditions are tightly coupled to the Northern Atlantic Oscillation (NAO) and years with positive NAO have stronger winds and a substantial increase in rainfall (Kotta et al. 2004). Moreover, cold winters alter the seasonal freshwater inflow, producing a spring freshet (Hanninen et al. 2000). In the Gulf, river discharges mix with brackish Baltic Sea water, yielding average surface salinity between 5.2 and 6.4 , whereas bottom layer salinity is $>7$. However, during spring, surface salinities $<2$ can be observed in the river plumes.

\section{Zooplankton monitoring data}

The zooplankton monitoring data from the Gulf of Riga is the most extensive dataset of zooplankton species composition and abundance in the Baltic Sea. Data were collected by the Estonian Marine Institute (UTEMI) and Institute of Food Safety, Animal Health and Environment in Latvia (BIOR). The coastal data originate mostly from Parnu Bay, covering areas up to $10 \mathrm{~m}$ deep. Samples were collected with a Juday $90 \mu \mathrm{m}$ net as a single haul from the bottom ( $1 \mathrm{~m}$ above the sea floor) to surface. Open Gulf data were collected with Juday 160 (mesh size $160 \mu \mathrm{m}$, upper ring [?] $37 \mathrm{~cm}$ ). Sample preparation for counting was performed according to HELCOM standardized methods (HELCOM 2017). During analysis, zooplankton were identified to species level or to the lowest possible taxonomic level and their number in subsample determined. The number of Copepoda was counted separately for each stage, i.e., nauplii NI-6, copepodites $\mathrm{CI}-\mathrm{V}$ and adult females and males CVI. The counting procedure in the sub-samples was repeated until the number of three dominant species reached 100 individuals. The individuals of large-sized zooplankton species (Cercopagis pengoi and Limnocalanus macrurus ) were counted in the whole sample. Finally, the biomass of each species was determined using individual wet weight factors (Hernroth 1985). Cercopagis pengoi biomass (BIOR data) was calculated using individual weight factor 0.4 according to Ojaveer (1997). Data covered the time period from 1957 to 2014. Seasonal data for May and August were consistently sampled both in 
the coastal and open gulf areas; therefore the data from these two months were used, consisting in total of 2118 profiles (970 coastal, 1148 open, 1108 in May, 1010 in August).

Trends in functional group richness and trait composition

The simplest approach to defining functional diversity is thefunctional group richness (FGR). To calculate the FGR for the samples, species were divided into basic functional groups. Functional groups were defined by combining higher level taxonomic classification (mostly Class) with the feeding mode. The prominent groups Cladocera and Copepoda were further classified into 'large' and 'small'. Values of a relatively simple set of functional traits was assigned to more frequently encountered zooplankton taxa (species or higher) in order to analyse the shifts in functional composition of communities in further detail (Table 1).

Table 1 . Functional traits used in this paper, and organization of trait table. Trait values are shown for 10 most frequent taxa in Gulf of Riga. "Complexity" is a four-level proxy for the complexity (body size, reproduction) of the organism: ' 1 ' - rotifers; '2' - cladocerans, '3' - copepods; '4' - other (more complex) organisms (e.g. Polychaeta, Meroplankton, Mollusca). Filtering and predation: $1=$ yes, $0=$ no.

\begin{tabular}{llllll}
\hline Taxa/Functional traits & Complexity & Filtering & Predation & Min. length (mm) & Max length (mm) \\
Eurytemora affinis & 3 & 1 & 0 & 0.35 & 1.25 \\
Copepoda & 3 & 1 & 0 & 0.4 & 1 \\
Acartia sp. & 3 & 1 & 1 & 0.29 & 1.3 \\
Bosmina (Eubosmina) coregoni & 2 & 1 & 0 & 0.15 & 0.8 \\
Synchaeta baltica & 1 & 1 & 0 & 0.19 & 0.35 \\
Keratella sp. & 1 & 1 & 0 & 0.13 & 0.43 \\
Amphibalanus improvisus & 4 & 1 & 0 & 0.15 & 0.4 \\
Bivalvia & 4 & 1 & 0 & 0.15 & 0.7 \\
Podon polyphemoides & 2 & 0 & 1 & 0.2 & 1 \\
Evadne nordmanni & 2 & 0 & 1 & 0.25 & 3 \\
Limnocalanus macrurus macrurus & 3 & 1 & 1 & 0.6 & \\
\hline
\end{tabular}

Principal coordinate analysis to reveal functional (dis)similarities between taxa

After the assembly of the functional trait table, Principal Coordinate Analysis (PCoA) of the species functional traits was used to construct a 'functional trait map' from the 204 taxa with complete set of trait information. Distance matrix for PCoA was calculated with Gower distance that allows different trait types (continuous, binary, categorical) to be combined. Minimum and maximum length were log transformed before calculating the distance. The first two principal coordinates were kept in PCoA to create a $2 \mathrm{D}$ representation of the functional differences between species.

Long-term shifts in the functional composition of communities

After the taxa had obtained coordinates in the PCoA, the functional composition was described by the position of the community in the PCoA plot. The position of the community was calculated as a mean position of the taxa in the sample with respect to A1 and A2, weighted by their relative abundances. Long-term trends (explanatory variable year) were then visualized and quantified by Generalized Additive Model (GAM) smooth functions (family Gaussian, link identity), using the community coordinates A1 or A2 in May or August as response variables. Models were fitted to A1 and A2 separately, since it is more difficult to visualize and interpret the temporal trends on a 2D surface. To analyse the trends in A1 and A2 independently was also meaningful, because the distribution of trait values along A1 and A2 is straightforward (feeding type varies along A1, complexity and body size vary along A2).

Environmental drivers and zooplankton functional composition

The environmental variables that have the potential to shape zooplankton communities (salinity, temperature, turbidity), as well as the proxies of eutrophication (chlorophyll $a$, dissolved oxygen) were not measured 
consistently during the monitoring cruises. The model data are therefore considered a realistic, and a more accurate (without measurement error) estimate of salinity, oxygen and temperature. Oxygen, temperature and salinity data originate from the 3D coupled sea-ice ocean model for Baltic Sea (BSIOM; Lehmann et al. 2014), which has a high spatial resolution $(2.5 \times 2.5$ grid cells $)$ and a $3 \mathrm{~m}$ depth resolution for the period of 1979-2014. Oxygen concentration was extracted from the model for the bottom layer, and salinity and temperature were calculated as average values of water column, matching the zooplankton observations (latitude, longitude, month). Winter air temperatures were obtained from three weather stations in the north-eastern part of Gulf of Riga ( Pärnu, Kihnu and Sõrve). The Baltic Sea Index (BSI; provided by A. Lehmann, Helmholtz Centre of Ocean Research), defined as the difference of normalized sea level pressure (SLP) anomalies between Oslo in Norway and Szczecin in Poland (Lehmann et al. 2002), was used as a proxy for large-scale atmospheric variability. To investigate the potential connections between environmental variables and zooplankton community composition, we used a hypothesis-driven approach.

\section{Hypothesis 1: Decreasing salinity promotes rotifers and cladocerans}

We expected the share of rotifers and cladocerans to be negatively affected by salinity (Gutierrez et al. 2018). To find support for H1, we looked for expected links between the interannual variations in community composition: the average position along the axis A2 that corresponded to the complexity, or relative share of rotifers and cladocerans in summer as a function of annual mean salinity in the study area.

\section{Hypothesis 2: Higher summer water temperature promotes smaller organisms}

We expected the community to change towards the dominance of smaller organisms with increasing temperature (Daufresne et al. 2009). H2 was tested similarly to H1, using water temperature as predictor.

Hypothesis 3: Milder winters and higher water temperature in May lead to higher functional richness (phenological shift).

The hypothesis that milder winters bring higher functional diversity in May was based on two assumptions or observations: 1) phenological shifts occur with milder winters and the summer-like communities will appear earlier and 2) during the summer the communities are usually functionally more diverse (Richardson 2008). To test H3, functional richness was correlated with winter air temperature and water temperature in May.

Hypothesis 4: Lower oxygen concentration in summer will have a negative effect on the functional richness.

Lower oxygen content in summer was expected to reduce the functional diversity. H4 was expected to be true in open gulf; therefore, only open gulf data were used.

\section{Sensitivity tests}

To assure that none of the long-term changes were caused by sampling or by taxonomic artefacts, sensitivity analyses were carried out, in which the extent of the repositioning of communities at the PCoA space was assessed while omitting one taxon at the time from the data. This analysis was done by same subsets of data as shown in Figure 3. Diagnostics plots were drawn for the most influential taxa (supplementary Fig. $\mathrm{X}$ ) that were selected after omitting a particular taxon. The A1 or A2 values of the selected samples had a Pearson's correlation with full community A1 or A2 values <0.9). No artefacts (i.e., sudden unexplainable appearance or disappearance of the taxon) were revealed during this test, although several taxa had a strong impact on the long term trend. Altogether 11 influential taxa were identified during this test in 19 cases, and in 5 cases, a long-term trend became notably stronger after excluding a single taxon (e.g. Synchaeta sp. and Acartia sp. in open sea area in May along PCoA axis 1 (Fig. S1c), or Bosmina sp. in open sea in August, along PCoA axis 1, Fig. S1g). All analyses were performed using the R software (version 3.4.0) and RStudio (version 1.1.442; R Development Core Team 2012). 


\section{Results}

Taxonomic composition of Gulf of Riga zooplankton

Altogether, 38 taxa occurred in the data, of which 22 were present in $>5 \%$ of the profiles. In coastal areas (970 profiles), the top taxa (based on frequency of occurrence in profiles) areCopepoda (mostly nauplial stages), Acartia spp.,Eurytemora affinis, Keratella quadrata, Synchaeta baltica , Bosmina (Eubosmina) coregoni , Bivalvia ,Synchaeta monopus, and Amphibalanus improvisus. In the open sea area (1148 profiles), the respective list of taxa isAcartia sp., E. affinis, Synchaeta sp.,Limnocalanus macrurus macrurus , $B$. coregoni,Keratella sp., Evadne nordmanni, Pleopis polyphemoides, Cyclops sp., and Bivalvia.

Filtering or mixed feeding type small copepods and filtering rotifers were the three functional groups present in nearly all samples.

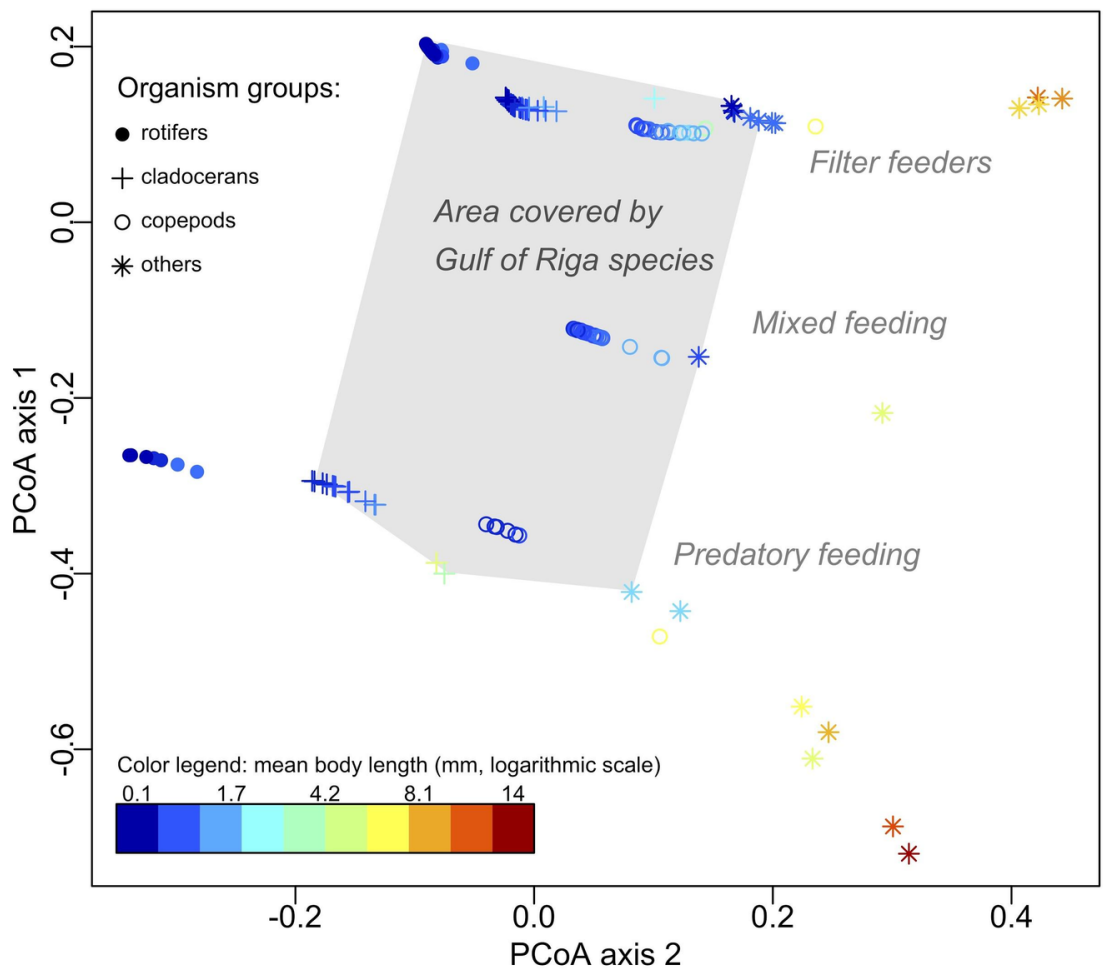

Figure 1 . Principal Coordinate Analysis (PCoA) of the functional trait values of Baltic Sea zooplankton. Coloured points correspond to individual taxa (species or higher, $n=204$ ). The effect of different traits on the PCoA results is visualized by symbols and colour: colour describes the mean body length (middle point between the minimum and maximum body size during life cycle); symbols indicate the large grouping of organism (four categories: rotifers, cladocerans, copepods, and others). Light grey polygon is a convex hull defined by the subset of taxa that were found in Gulf of Riga. Along the PCoA axis 1, the species were separated by the feeding type: values above the 0 belong to the filter feeding organisms, mixed feeding type is found between the 0 and -0.2 , and all points below -0.2 are the predators.

Long-term trends in functional group richness

During the investigated time period, the functional group richness (FGR) varied between the season and area (Fig. 2). In the 1960s, the spring time (May) FGR exhibited opposite patterns in the coastal and open sea areas. In the coastal area, FGR was initially lower (ca. 4) and increased during the decade, whereas 
in the open sea the FGR initially decreased from ca. 7 to 5 . After this time period, FGR followed similar patterns. In the coastal area a steep increase in FGR has occurred since the 1990s and in the open sea area FGR has increased gradually since the 1980s.

In August, FGR showed similar patterns in both coastal and open sea areas. Initially, late summer FGR decreased until the beginning of 1990s and was at its lowest in 1990, whereafter it increased in both areas until the early 2000. Since the peak in the mid-2000, a decrease has been recorded. In both areas, FGR was always higher in late summer.
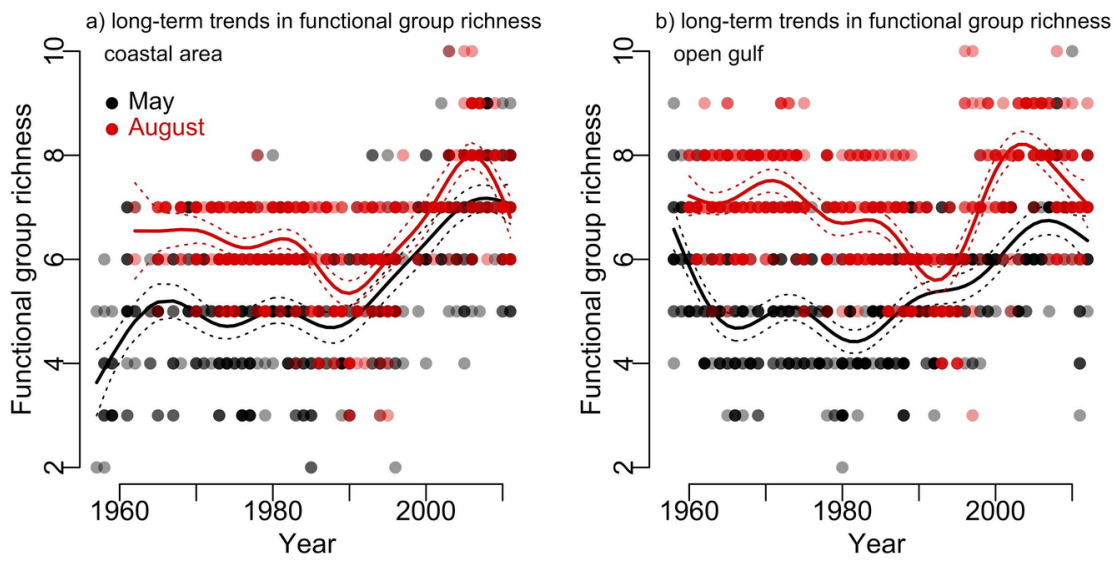

Figure 2 . Long-term trends in functional group richness during 1960-2010 in coastal areas (a), and in open gulf (b). Each dot represents the number of functional groups per sample, and the lines are respective smoothed curves against year (i.e. average).

Long-term shifts in trait composition

The significance of long-term variability was judged from the deviance explained by the GAM curves. Only the coastal community in August did not change over time, when judging from the GAM fit on A1 and A2 as a function of year (Figs. 3c, g). In all other cases (open gulf in August, and both open and coastal areas in May), pronounced long-term variability occurred both in A1 (mostly reflecting the feeding type) and A2 (mostly reflecting the complexity).

Most conspicuous trends in functional composition were the shift towards negative values of A1 indicating a shift from filtering organisms to mixed feeders and predators in the open sea late summer communities during the 1980s to early 2000 (August: Fig. 3d), although this trend reversed in early 2000 simultaneously with a shift towards more complex organisms (until 2000). Also in both areas in May (Figs. 3a, b), the long term trend was towards increasing share of mixed or predatory feeding type.

Significant long-term variability was also evident in A2 values. In the spring communities (May), the prominent long-term shift in complexity was towards higher share of simpler organisms (Figs. 3e, f). In August, the functional composition of both coastal and open area communities remained almost unchanged. 

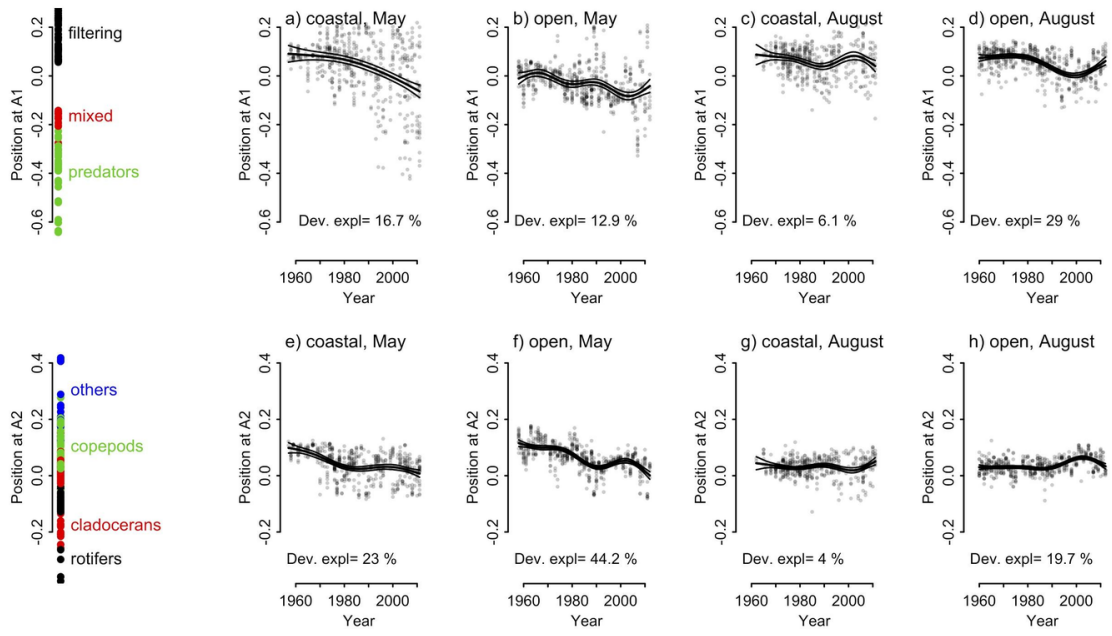

Figure 3. Long-term shifts in the position of communities with respect to functional trait map first (A1, upper row) and second coordinate (A2, lower row), in coastal and open gulf in May and August.

Long-term trends in the main organism groups

We compared the mean proportions of each groups' abundance (rotifers, cladocerans, copepods, others) to the total abundance of organisms in order to detect patterns in the long-term dynamics of the main groups. In the coastal area in May (Fig. 4a), the proportion of rotifers increased from 1960s onwards from ca. 40\% to ca. $70 \%$ of the whole community abundance; however, the proportion varied strongly over time. In the 1960s, copepods were dominating the community. Since then a large decrease in the abundance of copepods has been recorded in connection to an increase of rotifers, and more recently, an increase in the abundance of e.g., bivalves ('others'). Later in the summer (August) in the coastal area, the most notable change was the decrease in the proportion of cladocerans of their peak in the mid-1980s to very low abundances in the mid-1990s and beyond (Fig. 4b). After the mid-1990s, rotifers accounted for $>50 \%$ of the organisms recorded. In the open sea area in May (Fig. 4c), the community was mostly dominated by copepods until the 1980s, whereafter the proportion of rotifers increased and dominance relations started to shift from copepods to rotifers. Towards the end of the investigated time period, from ca. 2005, the proportion of copepods decreased by ca. $50 \%$, related to the increased proportion of 'others'. In August in the open sea area (Fig. 4d), the large decrease of rotifers from 1990s to 2010 gave rise to increasing dominance of cladocerans and copepods. 

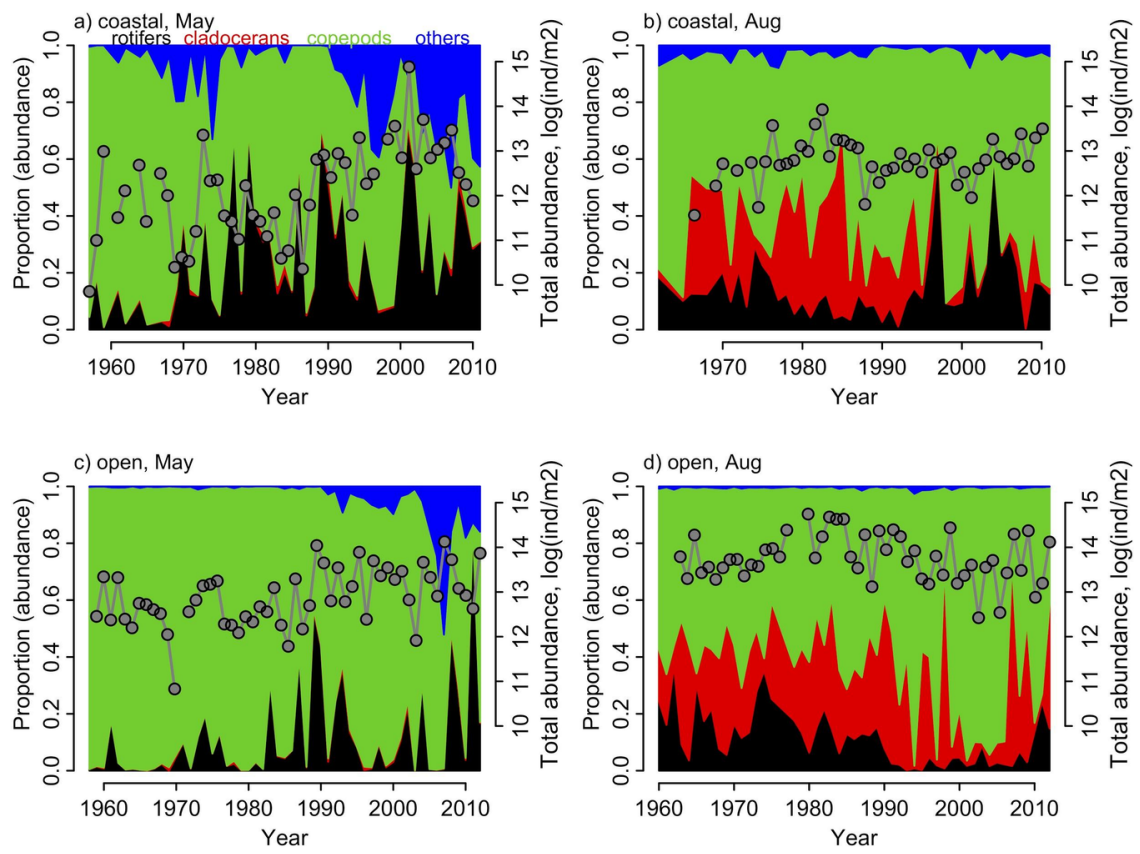

Figure 4. Annual mean length-adjusted abundance proportions of the main organism groups (rotifers=black, cladocerans $=$ red, copepods=green, others=blue) and total length-adjusted abundance of the zooplankton community (grey points).

Trends in relevant environmental drivers

Winters were generally harsh, but more variable before the 1990s. The winters 1990-1995 were relatively mild, and since then gradual cooling has occurred (Fig. 5a). The winter air temperatures largely follow the Baltic Sea index. Oxygen concentration was variable, yet slightly declining during the entire period 1978-2012, and no hypoxic or anoxic levels were estimated (Fig. 5b). Salinity peaked in the mid-1980s both in spring and summer, and in open and coastal areas, whereafter it declined until the mid-1990s and has fluctuated slightly since (Figs. 5c, d). In the spring, surface temperature fluctuated more until mid-1990s in both open and coastal sea areas, whereafter it was slightly increasing in the coastal area (Fig. 5e). 

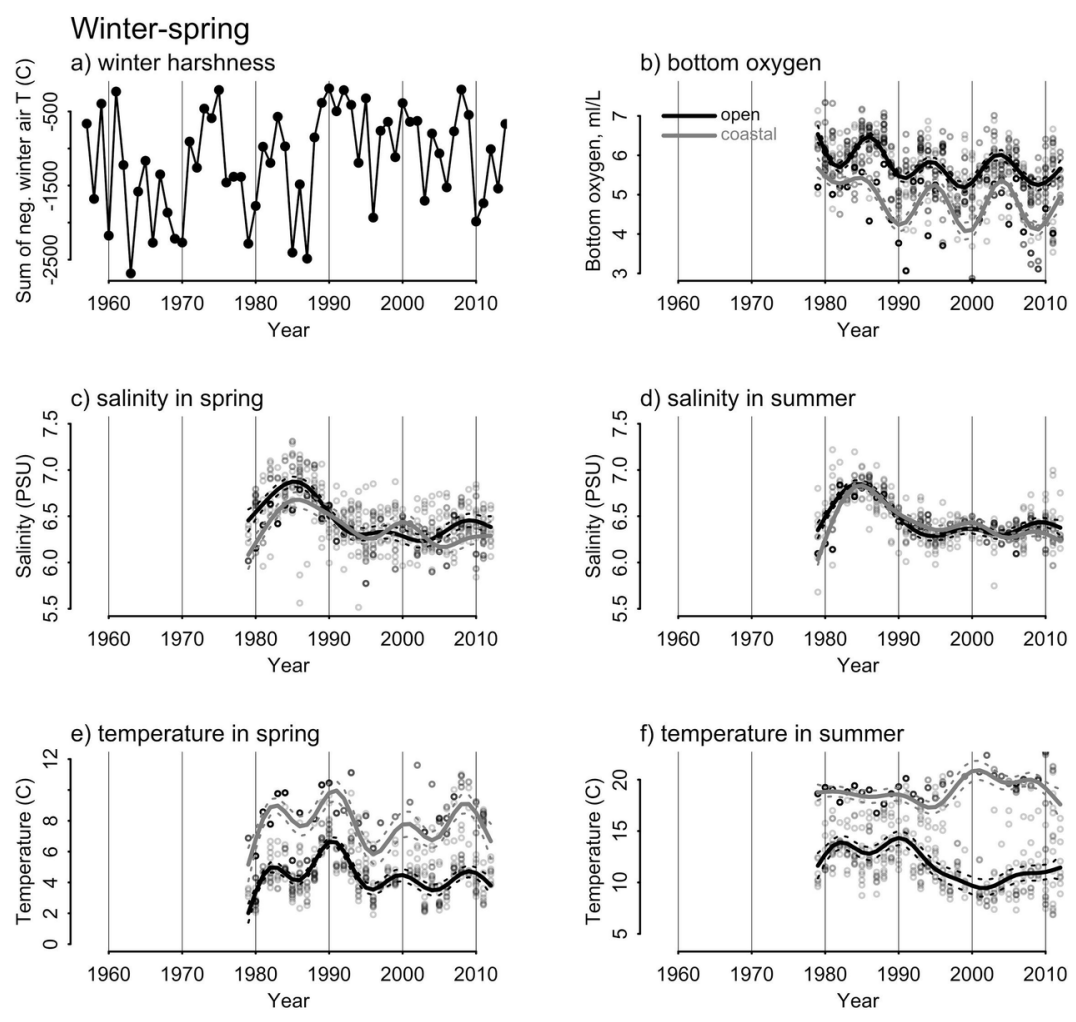

Figure 5. Long-term trends in the environment: a) winter air temperature (sum of negative temperatures); b) bottom oxygen concentration in late summer/August; c-d) salinity in May and August; and e-f) temperature in May and August. In figures b-f, the open sea area is denoted with black line, and the coastal area with grey line.

Functional composition and environmental factors

\section{Hypothesis 1: Salinity}

The share of cladocerans and rotifers was expected to be negatively affected by salinity. This hypothesis was, however, not supported. A negative link was found between salinity and A2 axis of PCoA, implying the dominance of simpler organisms as salinity increased (Fig. 6c). When looking at the proportions of individual groups, we found the proportion of rotifers to be positively correlated with salinity (Fig $7 \mathrm{~b}$ ). Proportion of cladocerans was highly variable, but there was no link to salinity (Fig. 7d). 

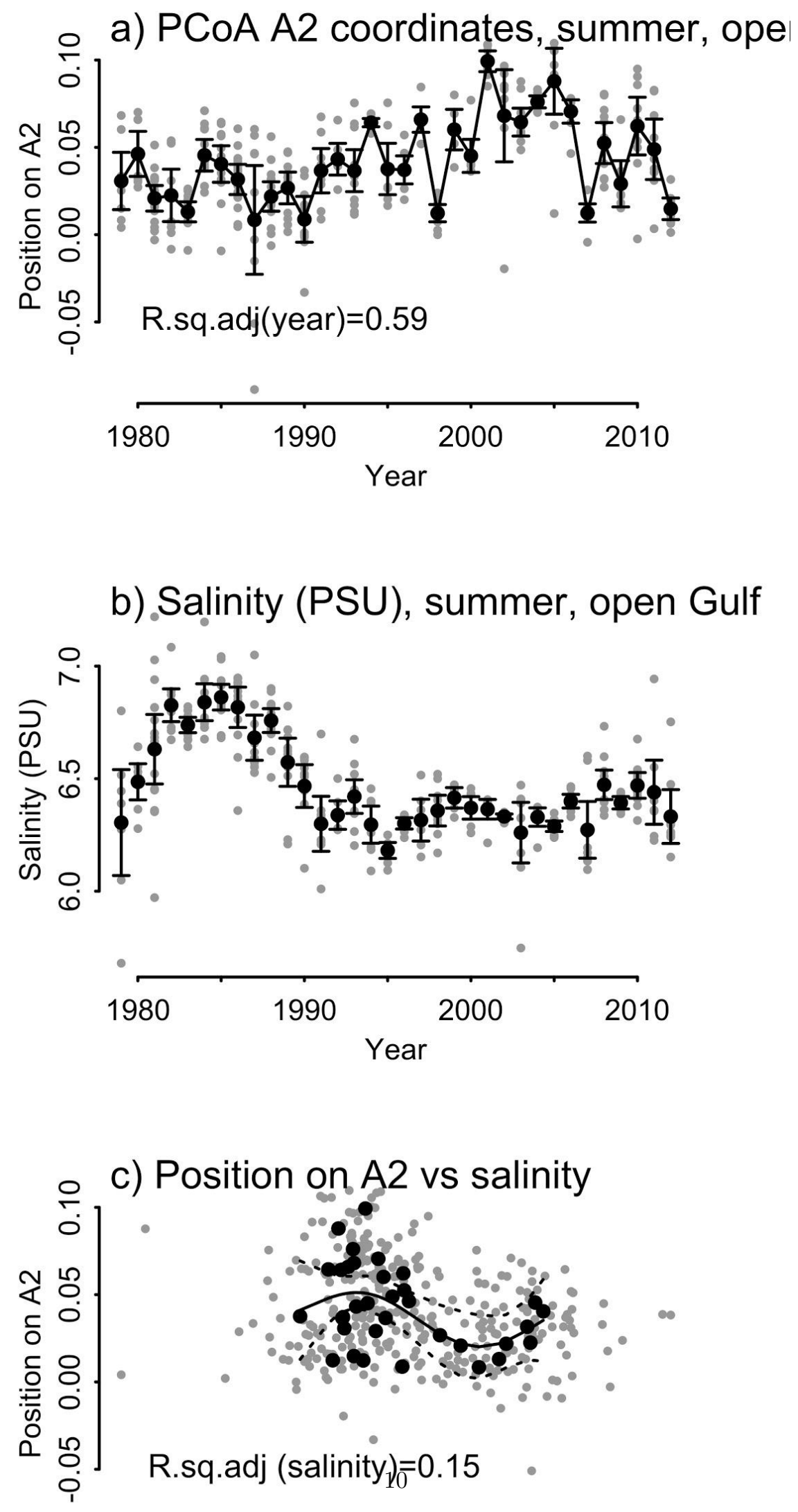

$\begin{array}{ccc}6.0 & 6.5 & 7.0\end{array}$


Figure 6 . The community composition as the position on the PCoA axis A2 (a) and its relation to salinity (b and $\mathrm{c}$ ).
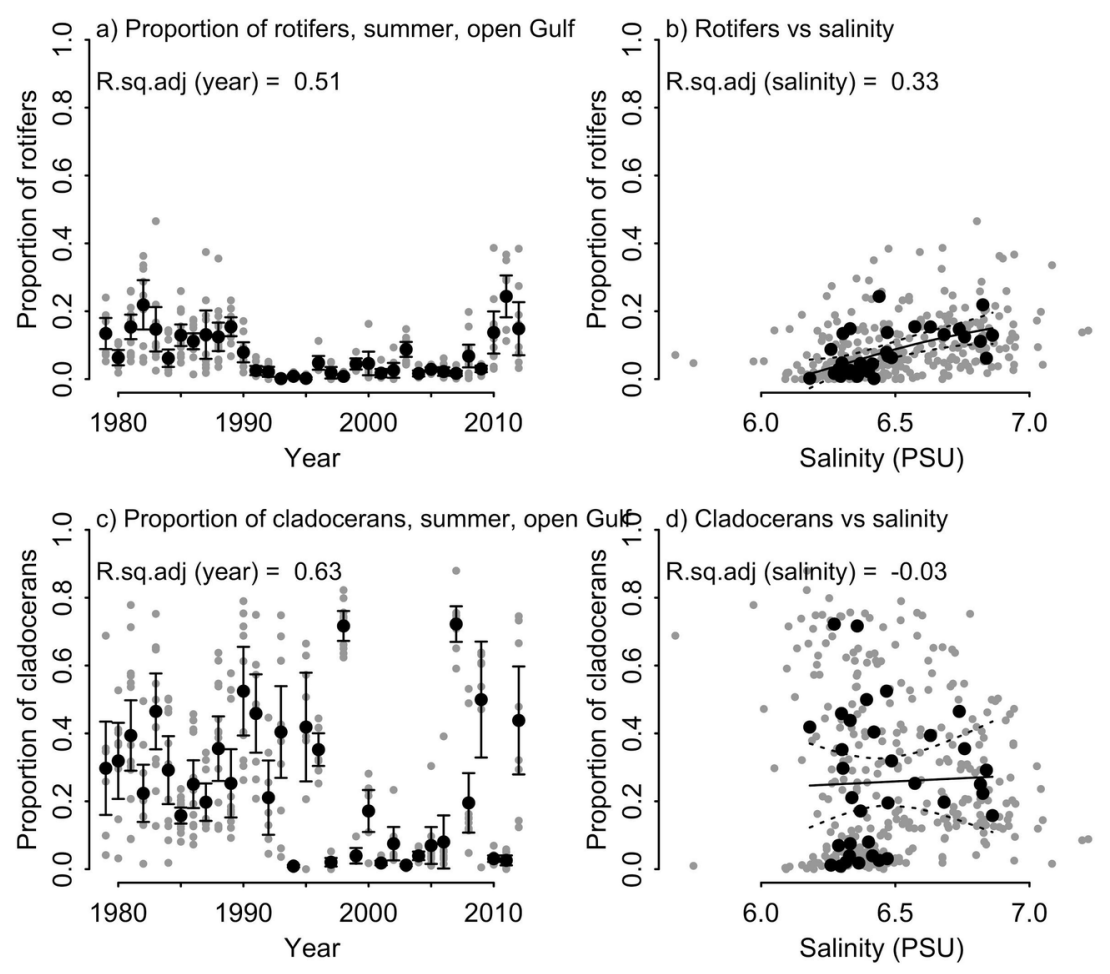

Figure 7. The effect of salinity on the main groups of interest; rotifera (a and b) and cladocera (c and d).

Hypothesis 2: Temperature

The community was expected to change towards dominance of smaller organisms with increasing temperature. This hypothesis was supported by the shifts in the community. The negative link between temperature and community position along A2 axis of PCoA implied on average lower complexity of organisms with warming (Fig. 8b). Looking only at groups, the relative proportion of cladocerans was particularly responsive to mean temperature (Fig. 8d). 

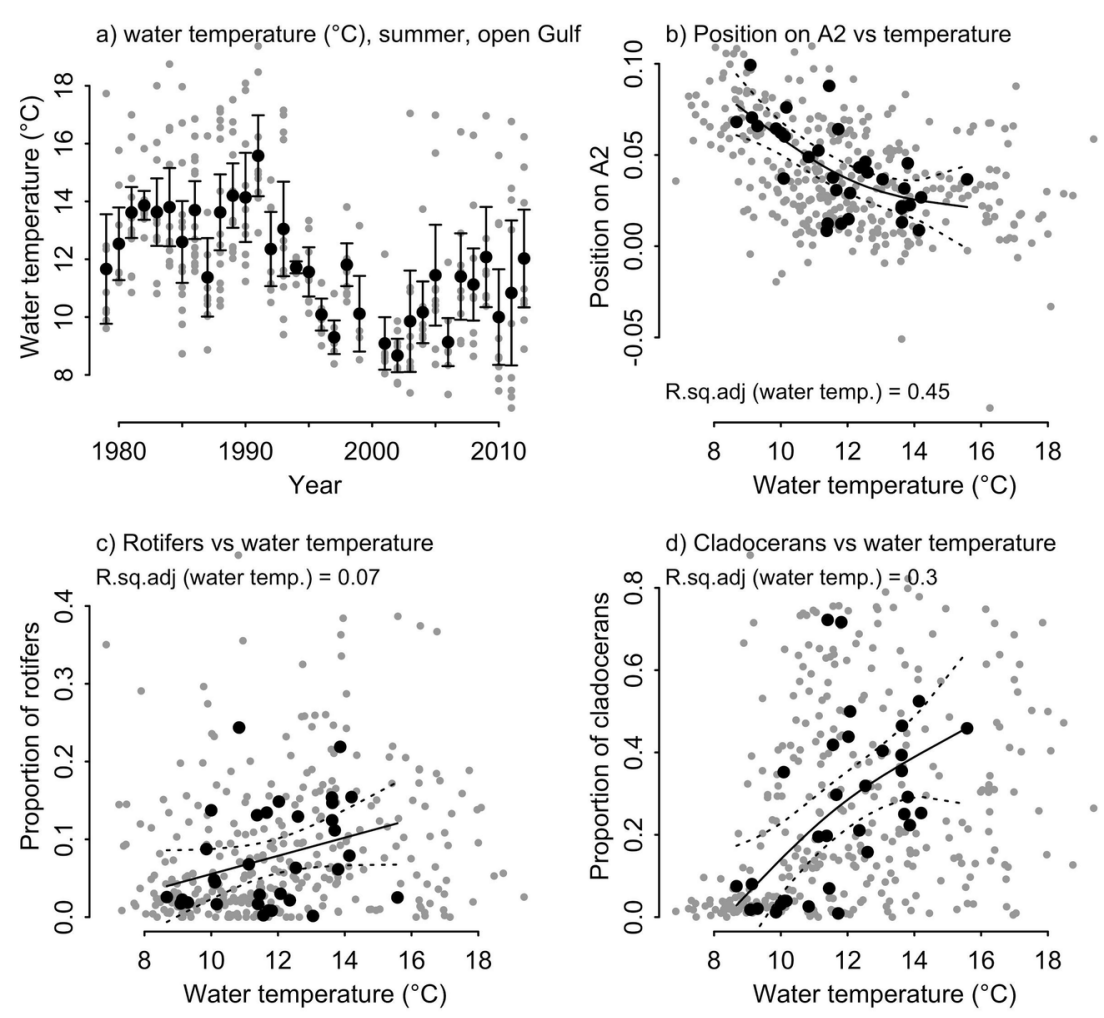

Figure 8. The effect of water temperature (a) on the community composition, and the (b) position on the PCoA plot axis A2, and the proportion of rotifers (c) and cladocerans (d) vs. water temperature.

\section{Hypothesis 3: Winter harshness}

Milder winters were expected to contribute to higher functional diversity $(\mathrm{H})$ in May. The data provided only modest support to this hypothesis, as in the open sea area, the higher functional diversity was observed with warmer winters (Fig. 9d). In coastal sea, the link with winter air temperature was unimodal; highest during 'average' winters (Fig. 9c). Correlation between the functional diversity and water temperature was not consistent with our expectation; negative in coastal area, unimodal in open gulf (Figs. 9e, f). 

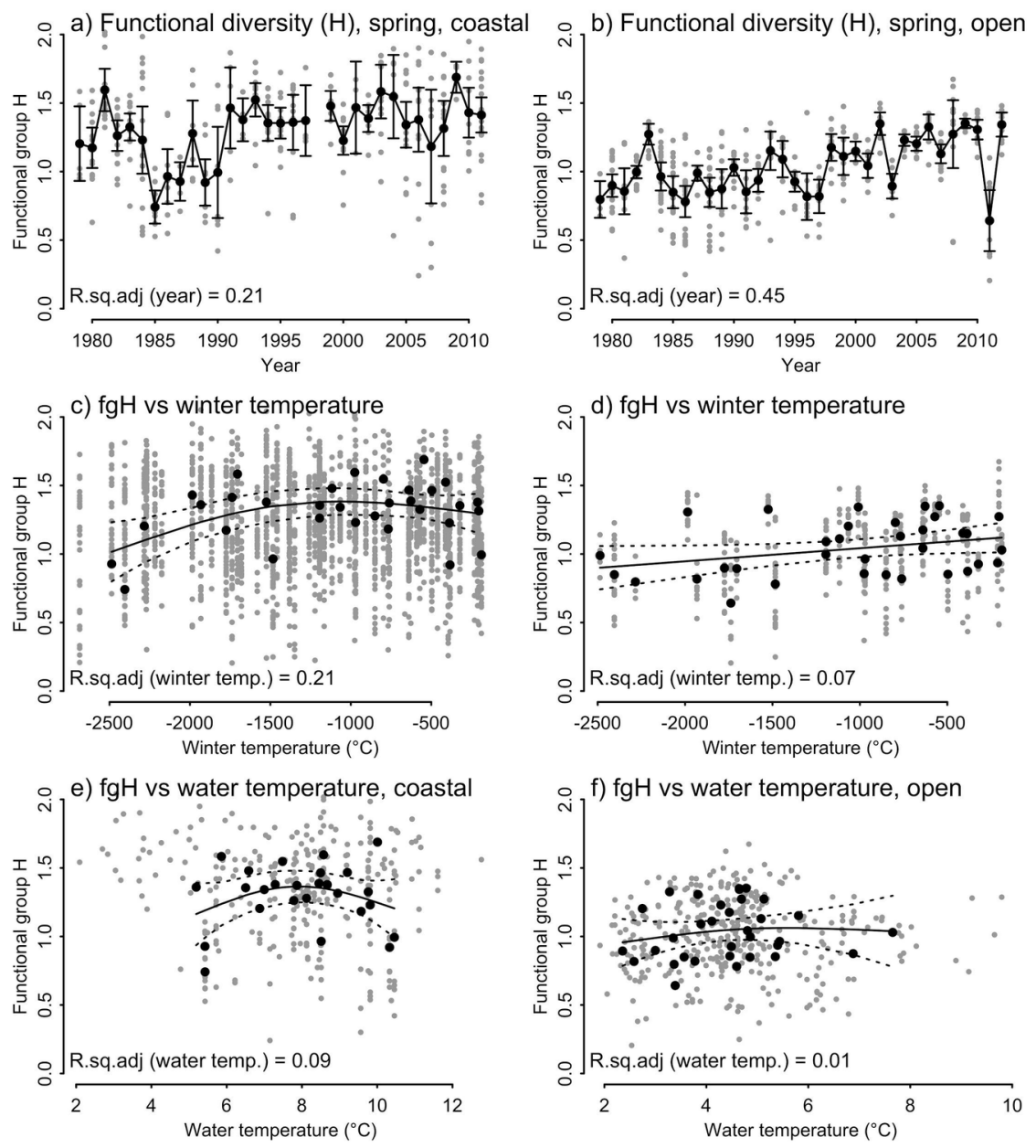

Figure 9. Functional diversity (fgH) in the spring (May) in the coastal (a) and open (b) sea areas, and its relation to winter air temperature in coastal and open sea areas (c and d, respectively) and water temperature in the spring (e and f).

Hypothesis 4: Oxygen

Lower oxygen content in late summer was expected to reduce the functional diversity $(\mathrm{H})$, however, only a weak link between $\mathrm{H}$ and oxygen concentration near the sea floor was found (Fig. 10c). 


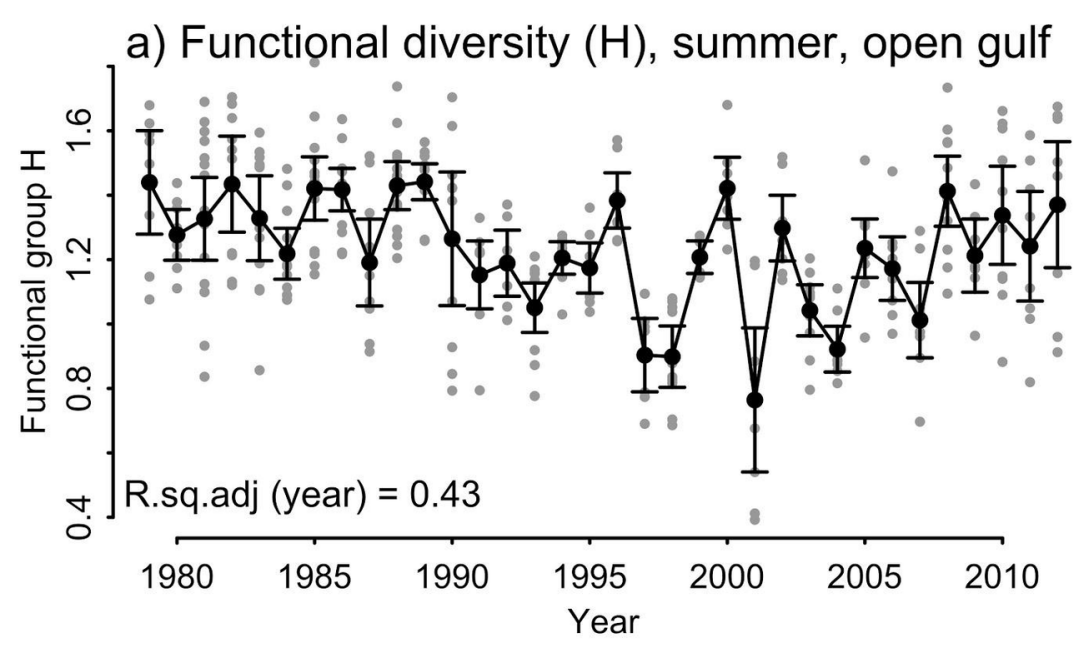

b) Bottom oxygen ( $\mathrm{ml} / \mathrm{L})$, summer, open

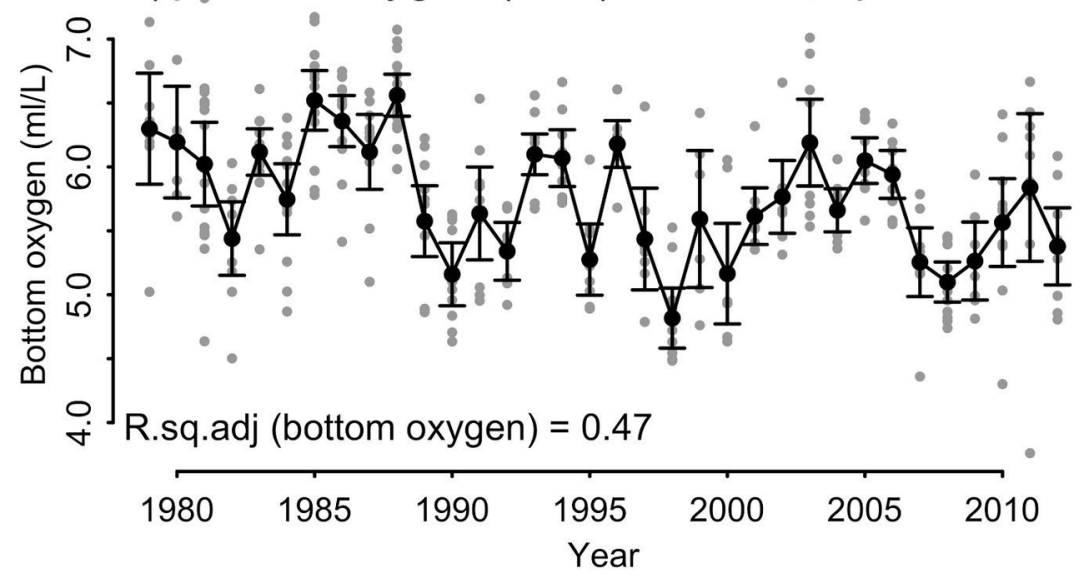

c) $\mathrm{fgH}$ vs bottom oxygen

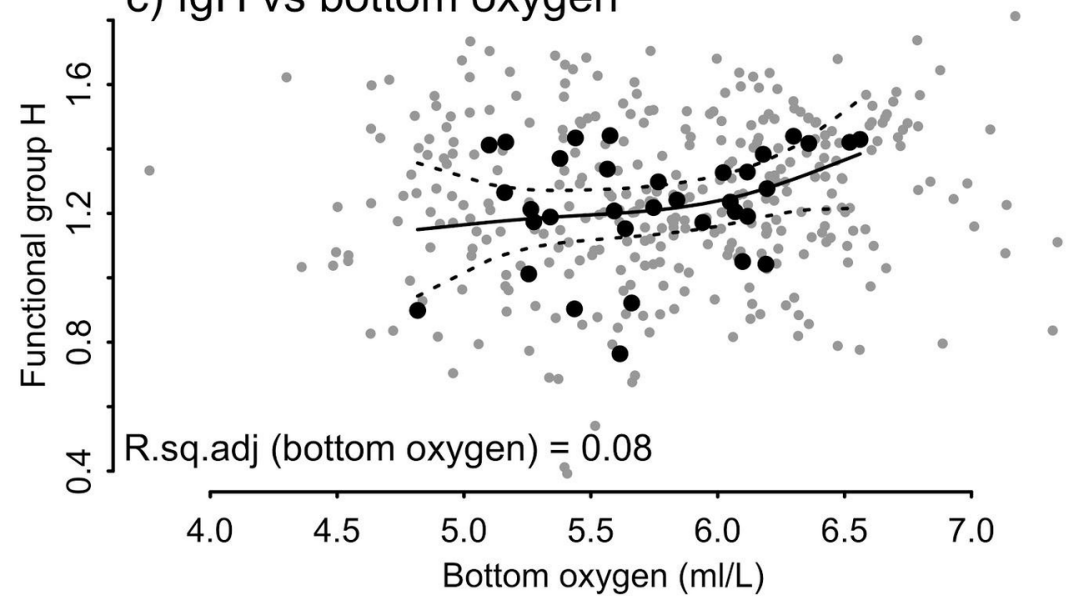

Figure 10. Functional diversity $(\mathrm{H})$ in August in the open sea area (a), bottom oxygen (b) and functional diversity relation to bottom oxygen concentration (c). 


\section{Discussion}

In this paper, we investigate changes using functional traits and groups that have taken place in the Gulf of Riga zooplankton communities during the past five decades in relation to environmental variables. One of the most significant changes was the considerable increase of the zooplankton functional groups (FGR) in coastal springtime communities, and dominance shifts in functional trait composition.

FGR and functional trait composition

In the spring, the functional group richness of zooplankton increased overall during the investigated time period 1960-2010; in the coastal area, the increase was nearly twofold. Several environmental factors caused the increase of the FGR in the springtime community. We found that the changes in salinity and temperature mainly impacted the community by increasing the abundance of simpler, smaller organisms. The higher nutrient load in the system in early spring increased the amount of functional groups. In the late summer, functional group richness gradually decreased from the 1970s and 1980s both in the open sea area and coastal area, respectively, until the 1990s where the richness was at its lowest. This most likely reflects the system response to eutrophication that has been extensive in the Baltic Sea since the 1960s (Cederwall \& Elmgren 1980; Andersen et al. 2016).

Regarding functional trait composition, the main long-term shift that occurred during 1960-2010 was the shift from a community dominated by filterers in the 1960s towards a mixed- and predator-dominated community in the early 2000. Also the complexity of the organisms changed from more complex groups (Copepoda) to a community dominated by cladocerans and rotifers. Rotifers are known to increase in murky lakes (Leechet al. 2018); they also respond to warming (Daufresne et al. 2009), and to eutrophication (Vehmaa et al. 2018). Gulf of Riga is still known to be one of the most eutrophicated basins in the Baltic Sea (HELCOM 2018), which is a likely reason for the strong increase in rotifers. Vehmaa et al. (2018) showed that also small-bodied cladoceran such as Bosmina (Eubosmina) maritima respond to eutrophication by increasing their abundance.

Zooplankton community structure

The large decrease in the proportion of copepods in both coastal and open sea springtime communities was among the most notable changes that took place in the zooplankton community structure. Supporting evidence has been found in the Baltic Sea (Suikkanen et al. 2013; Kuosaet al. 2017). The reason to the findings have been suggested to be rapid warming that is affecting animal size negatively (Daufresneet al. 2009). Overfishing could be another factor indirectly affecting copepod populations, by causing diminishing of cod populations, and thereby enabling planktivorous fish populations such as Baltic herring Clupea harengus harengus and sprat Sprattus sprattus to flourish (Casini et al. 2008; Ljunggren et al. 2010). Eutrophication can also affect copepod populations negatively via decreased food quality caused by harmful algae blooms, which have become more frequent in the Baltic Sea and globally (O'Neilet al. 2012). The decrease of copepods occurred simultaneously with the increasing proportion of rotifers and more complex organism groups, named 'others'. Especially in springtime in the coastal area, the peak of 'others' since ca. 1995 was likely mostly attributed to the appearance and rapid increase of Marenzelleria spp. larvae that are abundant in the water column from early spring (Kauppi et al.2018). Marenzelleria first appeared in the southern Baltic Sea in 1985 (Bick \& Burckhardt 1989), and has since then become a dominant component of the benthic ecosystem (Norkko et al. 2015).

Functional composition and environmental factors

We expected the abundance of small-bodied organisms, i.e. rotifers and cladocerans, to increase with decreasing salinity. Interestingly, the abundance of rotifers showed a slight increase in the late summer communities when salinity increased. The salinity change during the investigated time period was very small, however, only $<1$ unit, and the natural salinity variation that the organisms experience often exceeds this both seasonally, e.g., in spring during the emergence from sediment, and spatially, e.g., during diel vertical migration. Most Baltic organisms are euryhaline, and ecosystems such as the Baltic Sea, where the communities are 
already exposed to large variability regarding a range of environmental parameters, are often expected to be less impacted by future changes as the organisms are adapting to live in such variable conditions. The influence of indirect factors such as changes in food quality, quantity and predation pressure can have a large impact on the community as a result of changes in environmental parameters. Vehmaa et al. (2018) demonstrated that food quantity (given as chlorophyll $a$ and total organic carbon) increased following eutrophication, using sediment core analysis. However, food quality is also altered by eutrophication (O'Neil et al. 2012), as harmful algae blooms are known to increase in frequency, magnitude and duration (Huisman et al. 2018), also in the Gulf of Riga as shown by Jurgensone et al. (2011). For example, both phytoplankton and also microzooplankton biomass and community structure can significantly affect the structure of zooplankton community. Klais et al.(2016) show that especially nitrogen-fixers and mixotrophs have increased in the current study area, Gulf of Riga, between spring and late summer.

Also temperature can act directly or indirectly on zooplankton community structure; directly, because of the impact it has on the metabolism and reproduction of the organisms, and indirectly via the competition mechanisms when different zooplankton functional groups compete for prey. Increasing temperature brings along a larger share of smaller sized and lower complexity organisms, as is shown e.g. by Vuorinenet al. (1998), Suikkanen et al. (2013) and Mäkinenet al. (2017). Also in the Gulf of Riga, the share of lower complexity organisms - most often cladocerans and rotifers - increased simultaneously with temperature rise. The increasing share of low complexity organisms which leads to its dominance instead of larger organisms (copepods) has the potential to decrease the energy availability of higher trophic level organisms, thus causing changes in the food supply chain (Leech et al. 2018). Also the carbon transport from the sea surface to the bottom will likely be decreased, as copepods are responsible for a large part of the global carbon cycle (Jónasdóttir et al. 2015).

Based on the model estimations, we did not detect hypoxic conditions during the investigated time period. Overall, hypoxia is a large problem in the Baltic Sea, and in the future as a result of rising temperatures and accelerated eutrophication, hypoxic conditions are predicted to be even more common both in frequency and duration (Diaz \& Rosenberg 1995; Kabel et al. 2012). The declining oxygen concentration near the seafloor has the potential to reduce the functional diversity (Vaquer-Sunyer \& Duarte 2008). Via the benthic life stage that many zooplanktic organisms have, the zooplankton is strongly affected by the conditions near the sea floor. Where oxygen stress occurs, these low oxygen conditions near the seafloor have the potential to disturb the eggs and resting stages of organisms (Lutz et al. 1992). Most species resting stages and eggs are tolerant to low oxygen conditions, yet, with oxygen conditions declining further, the share of tolerant species is slowly reduced. E.g. the nauplii of copepods can hatch at very low oxygen concentrations $\left(0.3 \mathrm{ml} \mathrm{l}^{-1}\right)$, but under these near-anoxic conditions their development eventually ceases (Katajisto 2004). Also reduced diel vertical migration due to low oxygen levels can change the diversity along the oxygen gradient. The oxygen deficiency stress near the seafloor has the potential to weaken a niche by decreasing the share of species that inhabit the deeper layers and thus increasing the share of species that stay on or closer to the surface.

\section{Conclusions}

The essence of using functional traits is to characterize organisms by properties that capture essential aspects of diversity, rather than to analyse individual species. In the current paper, we have used traits to determine how the zooplankton community is associated with environmental gradients in a highly eutrophicated gulf. The benefit of looking into traits have revealed systematic changes in the current community - the long-term decrease of copepods, increase of rotifers and dominance shift. On the other hand, the proportion of simpler organisms have increased in spring, whereas the proportion of more complex organisms have increased in late summer. Salinity did not have a clear effect on our functional traits, which could be due to the fairly small fluctuations in the Baltic Sea salinity. Neither oxygen concentrations affected traits significantly, which may depend on the fact that oxygen was fairly stable in the used time series; planktonic organisms are also very much able to move away from hypoxic areas. Our data also suggest that organisms of low complexity will benefit from the climate-induced warming of the environment, whereas salinity and oxygen levels seem to have minor effect on the planktonic community in the Baltic Sea, here exemplified by Gulf of Riga basin. 


\section{Data accessibility}

Data used in this study will be deposited in the Dryad Digital Repository at the time of publication.

\section{References}

Andersen JH, Carstensen J, Conley DJ, Dromph K, Fleming-Lehtinen V, Gustafsson BG, Josefson AB, Norkko A, Villnäs A, Murray C (2016) Long-term temporal and spatial trends in eutrophication status of the Baltic Sea. Biol Rev 92: 135-149

Arula, T., Ojaveer, H., \& Klais, R. (2014). Impact of extreme climate and bioinvasion on temporal coupling of spring herring (Clupea harengus m.) larvae and their prey. Marine Environmental Research, 102, 102-109.

BACC II Author Team (2015) Second assessment of climate change for the Baltic Sea basin, Regional Climate Studies. Springer, Berlin 501 pp.

Belkin IM (2009) Rapid warming of large marine ecosystems. Progr Oceanogr 81: 207-213

Bick, A., Burckhardt R., (1989). Erstnachweis von Marenzelleria viridis (Polychaeta, Spionidae) für den Ostseeraum, mit einem Bestmmungschluessel der Spioniden der Ostsee. Mitt. Zool. Mus. Berl. 65, 2: 237-247

Carstensen J, Conley DJ, Bonsdorff E, Gustafsson BG, Hietanen S, Janas U, Jilbert T, Maximov A, Norkko A, Norkko J (2014) Hypoxia in the Baltic Sea: biogeochemical cycles, benthic fauna, and management. Ambio 43: $26-36$

Casini, M., Lövgren, J., Hjelm, J., Cardinale, M., Molinero, J. C., \& Kornilovs, G. (2008). Multi-level trophic cascades in a heavily exploited open marine ecosystem. Proceedings of the Royal Society B: Biological Sciences, 275(1644), 1793-1801.

Cederwall H, Elmgren R (1980) Biomass increase of benthic macrofauna demonstrates eutrophication of the Baltic Sea. Ophelia Suppl. 1: 87-304

Conley, D. J., Carstensen, J., Ærtebjerg, G., Christensen, P. B., Dalsgaard, T., Hansen, J. L., \& Josefson, A. B. (2007). Long-term changes and impacts of hypoxia in Danish coastal waters. Ecol Appl, 17(sp5), S165-S184.

Conley D, Bjorck S, Bonsdorff E, Carstensen J, Destouni G, Gustafsson BG, Hietanen S, Kortekaas M, Kuosa H, Meier HEM, Muller-Karulis B, Nordberg K, Norkko A, Nurnberg G, Pitkanen H, Rabalais NN, Rosenberg R, Savchuk OP, Slomp CP, Voss M, Wulff F, Zillen L (2009) Hypoxia-related processes in the Baltic Sea. Environ Sci Technol 43: 3412-3420

Daufresne M, Lengfellner K, Sommer U (2009) Global warming benefits the small in aquatic ecosystems. Proc Natl Acad Sci USA 106: 12788-12793

Diaz, R. J., \& Rosenberg, R. (1995). Marine benthic hypoxia: a review of its ecological effects and the behavioural responses of benthic macrofauna. Oceanography and marine biology. An annual review, 33, $245-03$.

Doney SC, Ruckelshaus M, Duffy JE, Barry JP, Chan F, English CA, Galindo HM, Grebmeier JM, Hollowed AB, Knowlton N, Polovina J, Rabalais NN, Sydeman WJ, Talley LD (2012). Climate change impacts on marine ecosystems. Ann Rev Mar Sci 4: 11-37

Edwards, M., \& Richardson, A. J. (2004). Impact of climate change on marine pelagic phenology and trophic mismatch. Nature ,430 (7002), 881.

Hanninen, J., Vuorinen, I., \& Hjelt, P. (2000). Climatic factors in the Atlantic control the oceanographic and ecological changes in the Baltic Sea. Limnology and Oceanography, 45(3), 703-710.

Hebert, M. P., Beisner, B. E., \& Maranger, R. (2016). Linking zooplankton communities to ecosystem functioning: toward an effect-trait framework. Journal of Plankton Research , 39 (1), 3-12. 
HELCOM thematic assessment of eutrophication 2011-2016. (2018). Supplementary report to the 'State of the Baltic Sea' report. Eutrophication Supplementary Report. Baltic Sea Environment Proceedings 156.www.helcom.fi/publications

Hernroth L (ed) (1985) Recommendations on methods for marine biological studies in the Baltic Sea. Mesozooplankton biomass assessment. Baltic Mar Biol Publ 10:1-32

Holopainen R, Lehtiniemi M, Meier HEM, Albertsson J, Gorokhova E, Kotta J, Viitasalo M (2016) Impacts of changing climate on the non-indigenous invertebrates in the northern Baltic Sea by end of the twenty-first century. Biol Invasions 10.1007/s10530-016-1197-z

Huisman, J., Codd, G. A., Paerl, H. W., Ibelings, B. W., Verspagen, J. M., \& Visser, P. M. (2018). Cyanobacterial blooms. Nature Reviews Microbiology, 16(8), 471.

Jonasdottir, S. H., Visser, A. W., Richardson, K., \& Heath, M. R. (2015). Seasonal copepod lipid pump promotes carbon sequestration in the deep North Atlantic. Proceedings of the National Academy of Sciences, 112(39), 12122-12126.

Jurgensone I, Carstensen J, Ikauniece A, Kalveka B (2011) Long-term changes and controlling factors of phytoplankton community in the Gulf of Riga (Baltic Sea). Estuaries and Coasts (2011) 34:1205-1219.

Kabel K, Moros M, Porsche C, Neumann T, Adolphi F, Andersen TJ, Siegel H, Gerth M, Leipe T, Jansen E, Damste JSS (2012) Impact of climate change on the Baltic Sea ecosystem over the past 1,000 years. Nat Clim Change 2: 871-874

Karlson K, Rosenberg R, Bonsdorff E (2002) Temporal and spatial large-scale effects of eutrophication and oxygen deficiency on benthic fauna in Scandinavian and Baltic waters: a review. Oceanogr Mar Biol 40: $427-489$

Katajisto, T. (2004). Effects of anoxia and hypoxia on the dormancy and survival of subitaneous eggs of Acartia bifilosa (Copepoda: Calanoida). Marine Biology, 145(4), 751-757.

Kauppi, L., Norkko, A., \& Norkko, J. (2018). Seasonal population dynamics of the invasive polychaete genus Marenzelleria spp. in contrasting soft-sediment habitats. Journal of Sea Research, 131, 46-60.

Klais, R., Norros, V., Lehtinen, S., Tamminen, T., \& Olli, K. (2017). Community assembly and drivers of phytoplankton functional structure. Functional Ecology, 31(3), 760-767.

Kotta, J., Simm, M., Kotta, I., Kanošina, I., Kallaste, K., \& Raid, T. (2004). Factors controlling long-term changes of the eutrophicated ecosystem of Pärnu Bay, Gulf of Riga. Hydrobiologia, 514(1-3), 259-268.

Kotta, J., Lauringson, V., Martin, G., Simm, M., Kotta, I., Herkül, K., \& Ojaveer, H. (2008). Gulf of Riga and Pärnu Bay. In Ecology of Baltic coastal waters (pp. 217-243). Springer, Berlin, Heidelberg.

Kuosa, H., Fleming-Lehtinen, V., Lehtinen, S., Lehtiniemi, M., Nygård, H., Raateoja, M., .. \& Suikkanen, S. (2017). A retrospective view of the development of the Gulf of Bothnia ecosystem. Journal of Marine Systems, 167, 78-92.

Leech, D. M., Pollard, A. I., Labou, S. G., \& Hampton, S. E. (2018). Fewer blue lakes and more murky lakes across the continental US: Implications for planktonic food webs. Limnology and Oceanography, 63(6), 2661-2680.

Lehmann A, Krauss W, and Hinrichsen H-H (2002) Effects of remote and local atmospheric forcing on circulation and upwelling in the Baltic Sea. Tellus 54: 299-316.

Lehmann A, Getzlaff K, Harlass J (2011) Detailed assessment of climate variability in the Baltic Sea area for the period 1958 to 2009. Clim Res 46: 185-196 
Lehmann A, Hinrichsen H-H, Getzlaff K, Myrberg K (2014) Quantifying the heterogeneity of hypoxic and anoxic areas in the Baltic Sea by a simplified coupled hydrodynamic-oxygen consumption model approach. J Mar Syst 134: 20-28

Leppäranta M, Myrberg K (2009) Physical oceanography of the Baltic Sea. Springer-Praxis Books in Geophysical Sciences. Berlin, Germany, Springer- Berlin. 378 pp.

Ljunggren, L., Sandström, A., Bergström, U., Mattila, J., Lappalainen, A., Johansson, G., .. \& Eriksson, B. K. (2010). Recruitment failure of coastal predatory fish in the Baltic Sea coincident with an offshore ecosystem regime shift. ICES Journal of Marine Science, 67(8), 1587-1595.

Lutz, R. V., Marcus, N. H., \& Chanton, J. P. (1992). Effects of low oxygen concentrations on the hatching and viability of eggs of marine calanoid copepods. Marine Biology, 114(2), 241-247.

MacKenzie BR, Schiedeck D (2007) Daily ocean monitoring since 1860s shows record warming on northern European seas. Glob Change Biol 13: 1335-1347

Mäkinen, K., Vuorinen, I., \& Hänninen, J. (2017). Climate-induced hydrography change favours small-bodied zooplankton in a coastal ecosystem. Hydrobiologia, 792(1), 83-96.

Meier HEM, Hordoir R, Andersson HC, Dieterich C, Eilola K, Gustafsson BG, Höglund A, Schimanke S (2012) Modeling the combined impact of changing climate and changing nutrient loads on the Baltic Sea environment in an ensemble of transient simulations for 1961-2099. Clim Dynam 39: 2421-2441

Norkko J, Gammal J, Hewitt JE, Josefson AB, Carstensen J, Norkko A (2015) Seafloor ecosystem function relationships: in situ patterns of change across gradients of increasing hypoxic stress. Ecosystems 18:14241439

Ojaveer, H. (1997). Environmentally induced changes in distribution of fish aggregations on the coastal slope in the Gulf of Riga. In Proceedings of the $14^{\text {th }}$ Baltic Marine Biologists Symposium (Ojaveer, E., ed.), Pärnu, Estonia, 5-6 August 1995, pp. 170-183.

O'Neil, J. M., Davis, T. W., Burford, M. A., \& Gobler, C. J. (2012). The rise of harmful cyanobacteria blooms: the potential roles of eutrophication and climate change. Harmful Algae, 14, 313-334.

Richardson AJ (2008) In hot water: Zooplankton and climate change. ICES Journal of Marine Science 65: $279-295$

Sherman, K., Solow, A., Jossi, J., \& Kane, J. (1998). Biodiversity and abundance of the zooplankton of the Northeast Shelf ecosystem. ICES Journal of Marine Science, 55(4), 730-738.

Suikkanen, S., Pulina, S., Engström-Öst, J., Lehtiniemi, M., Lehtinen, S., \& Brutemark, A. (2013). Climate change and eutrophication induced shifts in northern summer plankton communities. PLoS one, 8(6), e66475.

Thomas CD, Cameron A, Green RE, Bakkenes M, Beaumont LJ, Collingham YC, Erasmus BFN, Siqueira MFD, Grainger A, Hannah L, Hughes L, Huntley B, Jaarsveld ASV, Midgley GF, Miles L, Ortega-Huerta MA, Peterson AT, Phillips OL, Williams SE (2004) Extinction risk from climate change. Nature 427: 145-148

Vaquer-Sunyer, R., \& Duarte, C. M. (2008). Thresholds of hypoxia for marine biodiversity. Proceedings of the National Academy of Sciences, 105(40), 15452-15457.

Vehmaa, A., Katajisto, T., \& Candolin, U. (2018). Long-term changes in a zooplankton community revealed by the sediment archive. Limnology and Oceanography, 63(5), 2126-2139.

Vuorinen I, Hanninen J, Viitasalo M, Helminen U, Kuosa H (1998) Proportion of copepod biomass declines with decreasing salinity in the Baltic Sea. ICES Journal of Marine Science 55 (4), 767-774. 